\title{
ABORDAGEM DA VIOLÊNCIA INFANTIL NA ESTRATÉGIA SAÚDE DA FAMÍLIA: FATORES INTERVENIENTES E ESTRATÉGIAS DE ENFRENTAMENTO
}

\author{
APPROACH TO CHILD VIOLENCE IN THE FAMILY \\ HEALTH STRATEGY: INTERFERING FACTORS AND \\ COPING STRATEGIES
}

\section{ENFOQUE DE LA VIOLENCIA INFANTIL EN LA ESTRATEGIA DE SALUD FAMILIAR: LOS FACTORES INTERMEDIOS Y LAS ESTRATEGIAS DE AFRONTAMIENTO}

\author{
Ana Lícia Barbosa Serra Silva ${ }^{1}$ \\ Laura Cristinne Santos Macatrão Bacellar Couto ${ }^{2}$ \\ Mikaeli Macêdo de Oliveira ${ }^{3}$ \\ Fernanda Cláudia Miranda Amorim ${ }^{4}$ \\ Juliana Macêdo Magalhães ${ }^{5}$ \\ Kayo Henrique Jardel Feitosa Sousa ${ }^{6}$ \\ Carolinne Kilcia Carvalho Sena Damasceno ${ }^{7}$
}

Como citar este artigo: Silva ALBS, Couto LCSMB, Oliveira MM, Amorim FCM, Magalhães JM, Sousa KHJF, et al. Abordagem da violência infantil na Estratégia Saúde da Família: fatores intervenientes e estratégias de enfrentamento. Rev baiana enferm. 2021;35:e42348.

Objetivo: identificar, na percepção de enfermeiros, os fatores intervenientes e as estratégias empregadas para a abordagem da violência infantil na Estratégia Saúde da Família. Método: estudo qualitativo com 22 enfermeiros de Teresina, Piauí. Os dados foram coletados em outubro de 2019, mediante entrevistas individuais orientadas por um roteiro semiestruturado, submetidas à análise de conteúdo temática. Resultados: os enfermeiros revelaram inabilidade para lidar com situações de violência infantil. Eles buscavam abordar esses casos por meio de estratégias pautadas no diálogo, no trabalho interprofissional e na intersetorialidade. Considerações finais: foram fatores intervenientes para a abordagem da violência infantil na Estratégia Saúde da Família, o (não)reconhecimento de sinais de abuso infantil, as barreiras para o estabelecimento de vínculo com as famílias e dificuldades de interlocução na rede assistencial. As estratégias para o enfrentamento da violência infantil utilizadas foram trabalho interprofissional, cuidado holístico, articulação com a rede intersetorial e diálogo com a família.

Descritores: Enfermagem. Maus-Tratos Infantis. Estratégia Saúde da Família. Saúde da Criança. Saúde Pública.

Estudante de Enfermagem. Centro Universitário Uninovafapi. Teresina, Piauí, Brasil. https://orcid.org/0000-0002-7566-2602.

Estudante de Enfermagem. Centro Universitário Uninovafapi. Teresina, Piauí, Brasil. https://orcid.org/0000-0003-4524-196X.

Estudante de Enfermagem. Centro Universitário Uninovafapi. Teresina, Piauí, Brasil. https://orcid.org/0000-0002-8887-7|86.

Enfermeira. Mestre em Enfermagem. Professora do Centro Universitário Uninovafapi. Teresina, Piauí, Brasil. https://orcid.org/0000-0002-1648-5298.

Enfermeira. Mestre em Saúde da Família. Doutora em Engenharia Biomédica. Professora do Centro Universitário Uninovafapi. Teresina, Piauí, Brasil. https://orcid. org/0000-000 I-9547-9752.

6 Enfermeiro. Mestre em Enfermagem. Universidade Federal do Rio de Janeiro. Rio de Janeiro, Rio de Janeiro, Brasil. kayohenriquejardel@gmail.com. https://orcid. org/0000-0002-0901-7752.

Enfermeira. Mestre em Saúde da Família. Professora do Centro Universitário Uninovafapi. Teresina, Piauí, Brasil. http://orcid.org/0000-000 I-5766-5984. 
Objective: identifying, in the perception of nurses, the intervening factors and strategies used to approach child violence in the Family Health Strategy. Method: a qualitative study with 22 nurses from Teresina, Piaui. Data were collected in October 2019, through individual interviews guided by a semi-structured script, submitted to Thematic Content Analysis. Results: nurses revealed inability to deal with situations of child violence. They sought to approach these cases through strategies based on dialogue, interprofessional work and intersectoriality. Final thoughts: there were intervening factors for the approach of child violence in the Family Health Strategy, the (non-recognition of signs of child abuse), the barriers to establishing bonds with families and difficulties in interlocution in the care network. The strategies for coping with child violence were interprofessional work, holistic care, articulation with the intersectoral network and dialogue with the family.

Descriptors: Nursing. Child Abuse. Family Health Strategy. Child Health. Public Health.

Objetivo: identificar, en la percepción de las enfermeras, los factores y estrategias intermedios utilizados para abordar la violencia infantil en la Estrategia de Salud Familiar. Método: se trata de un estudio cualitativo con 22 enfermeras de Teresina, Piaui. Los datos fueron recopilados en octubre de 2019, a través de entrevistas individuales guiadas por un guion semiestructurado, sometidos al análisis temático de contenidos. Resultados: las enfermeras revelaron incapacidad para lidiar con situaciones de violencia infantil. Trataron de abordar estos casos a través de estrategias basadas en el diálogo, el trabajo interprofesional y la intersectorialidad. Consideraciones finales: fueron factores intermedios para el enfoque de la violencia infantil en la Estrategia de Salud Familiar, el (no reconocimiento de signos de abuso infantil), las barreras para establecer vínculos con las familias y las dificultades de interlocución en la red de atención. Las estrategias para hacer frente a la violencia infantil fueron el trabajo interprofesional, el cuidado bolístico, la articulación con la red intersectorial y el diálogo con la familia.

Descriptores: Enfermería. Abuso de Menores. Estrategia de Salud Familiar. Salud Infantil. Salud Pública.

\section{Introdução}

A violência é considerada, no cenário nacional e mundial, problema de saúde pública ${ }^{(1-2)}$. A violência infantil é todo tipo de ação ou omissão que possa prejudicar o bem-estar, a integridade física ou psicológica, a liberdade ou o direito ao crescimento e ao desenvolvimento da criança ${ }^{(3)}$.

No Brasil, foram registrados 159.063 casos de violações aos direitos humanos no ano de 2019. Dentre estes, 86.837 foram denúncias que envolviam crianças e adolescentes, o equivalente a 55\% do total e a um aumento de 13,9\% em relação ao ano anterior. No tocante à distribuição por sexo, 55\% das vítimas eram meninas. Desse total, 38\% foram casos de negligência, $23 \%$ violência psicológica, 21\% violência física, $11 \%$ violência sexual; violência institucional e exploração do trabalho representaram 3\%, respectivamente, e outros tipos de violação aos direitos da criança e do adolescente, 1\%. Ressalta-se que houve maior agravamento dos casos de negligência quando comparado aos dados do ano anterior e há possibilidade de sobreposição de tipos de violência ${ }^{(2)}$.

Para melhor entender o expressivo aumento dos casos de violência infantil e suas interconexões, este estudo ancora-se na perspectiva de que qualquer criança é vulnerável à violência, e que esta possui uma dimensão individual e outra coletiva. A dimensão individual considera o conhecimento dos pais e/ou responsáveis e a possibilidade de acesso a esse, tendo em vista que condiciona a capacidade transformativa de comportamentos. Por outro lado, a dimensão coletiva envolve, por intermédio da sociedade, a garantia de desenvolvimento saudável e o exercício pleno de cidadania, com base em políticas de acesso à saúde, educação, cultura e renda - entre outros direitos constitucionais -, além de políticas de enfrentamento à violência, que inclui a capacitação profissional para a assistência à criança ${ }^{(4)}$.

A violência infantil, além de constituir uma realidade dolorosa, traz consequências devastadoras ao longo da vida, tanto de ordem física como psicossocial. Na adolescência, o aumento da morbimortalidade observado nas duas últimas décadas está relacionado, em maior parte, às consequências da violência, como ferimentos, deficiências, homicídios, mas também por adoecimentos decorrentes de condições de vida precárias, suicídios e acidentes ${ }^{(5)}$. 
Problemas sociais, emocionais e psicológicos $^{()}$, manifestados por meio da adoção de comportamentos de risco à saúde - como abuso de álcool e outras drogas, prostituição, gravidez precoce e problemas de saúde mental, como ansiedade, transtorno depressivo, comportamento agressivo e até tentativa de suicídio ${ }^{(7)}-$, podem estar relacionados à violência infantil. Esta pode ainda resultar em impactos negativos no desempenho escolar ${ }^{(8)}$ e na adoção de comportamentos violentos na vida adulta ${ }^{(9)}$, inclusive no namoro ${ }^{(10)}$.

A violência infantil é caracterizada como um problema de saúde pública de natureza multidimensional. Apresenta inúmeras variáveis e afeta todos os níveis socioeconômicos e culturais da sociedade. Tais razões torna necessária a intervenção de uma equipe multiprofissional e interdisciplinar, com atuação conjunta, coordenada e interligada de todos os serviços assistenciais ${ }^{(5,11)}$.

Por representar uma vivência negativa na vida do indivíduo, a possibilidade de uma criança superar essa experiência dolorosa depende da observância dos elementos que integram a sua rede de proteção e cuidado, nela incluída a assistência à saúde ${ }^{(3,9,11)}$. Visto que o Sistema Único de Saúde (SUS) tem um papel importante na prevenção e no enfrentamento à violência e na atenção integral às pessoas que vivenciaram tal situação, o Ministério da Saúde do Brasil, no ano de 2010, lançou a Linha de Cuidado para a Atenção Integral à Saúde de Crianças, Adolescentes e suas Famílias em Situação de Violências: orientação para gestores e profissionais de saúde ${ }^{(12)}$.

Nesse sistema, a Atenção Primária à Saúde (APS) é o primeiro nível de atenção, constituindo-se porta de entrada preferencial nas redes de atenção à saúde. Tal situação ocorre pelo fato de as equipes de Estratégia Saúde da Família (ESF) - apoiadas pelo Núcleo de Apoio à Saúde da Família (NASF) -, estarem inseridas geograficamente próximas dos domićlios familiares. Isso pode favorecer a identificação de sinais e sintomas de violência infantil, assim como estabelecer o acolhimento, o atendimento adequado desde o diagnóstico aos cuidados em saúde e, sobretudo, notificar os casos e encaminhar para a rede de cuidados e de proteção social ${ }^{(12)}$.
No âmbito da APS e da vigilância em saúde, o enfermeiro - como membro da equipe de saúde - tem responsabilidades de cuidado e suporte humanizado à criança e sua família, valorizando o bem-estar biopsicossocial, identificando e intervindo em necessidades e vulnerabilidades ${ }^{(13)}$. No entanto, relatório da European Union Agency for Fundamental Rights revela que esses profissionais apresentam dificuldades em reconhecer os sinais de violência infantil ${ }^{(14)}$. Diante disso, é de extrema importância que o enfermeiro, assim como os demais membros da equipe de saúde, esteja preparado para atender crianças em situação de risco. Estudo destacou que esse profissional apresenta habilidades para prestar cuidados de promoção e prevenção de danos à saúde, realizar ações de proteção, identificar e notificar casos ou suspeita de violência contra a criança ${ }^{(15)}$.

Apesar da existência de estudos sobre a violência infantil, esta proposta vai além de olhar, na perspectiva de enfermeiros atuantes na ESF, para a assistência de enfermagem nas situações de violência infantil. Propõem-se reflexões sobre como os profissionais, na vanguarda da rede intersetorial de atenção à saúde da criança, vêm enfrentando, no dia a dia, as situações de violência infantil. Assim, questionou-se: Quais os fatores intervenientes na abordagem às situações de violência infantil e as estratégias empregadas por enfermeiros da ESF para o seu enfrentamento? Apresenta-se, nessa perspectiva, elementos do processo de trabalho do enfermeiro que podem, porventura, atuar como facilitadores e/ou barreiras do cuidado.

Dessarte, o objetivo deste estudo foi identificar, na percepção de enfermeiros, os fatores intervenientes e as estratégias empregadas para a abordagem da violência infantil na Estratégia Saúde da Família.

\section{Método}

Trata-se de um estudo qualitativo realizado em seis Unidades Básicas de Saúde (UBS) do Município de Teresina, Piauí, em outubro de 2019. 
Os participantes deste estudo foram 22 enfermeiros que atuavam na ESF da capital piauiense. Atenderam ao critério de inclusão: ser enfermeiro, funcionário da UBS com atuação na equipe de ESF há pelo menos um ano. Excluíram-se enfermeiros ausentes no período da coleta de dados, devido a licença das atividades laborais por qualquer motivo.

O número de enfermeiros convidados a participar deste estudo buscou atender a representatividade coletiva e a profundidade dos sentidos ${ }^{(16)}$. Foi utilizado o conhecimento empírico para interromper a captação de novos participantes, quando se alcançou representatividade das falas e reincidência das informações obtidas.

A coleta de dados ocorreu por meio de entrevistas individuais semiestruturadas, com duração média de 15 minutos, orientadas por um roteiro composto por seis questões, para traçar o perfil dos enfermeiros, e quatro questões abertas, com o objetivo de elucidar o fenômeno na percepção deles. Essas questões envolviam falar sobre o que pensavam acerca da violência infantil, descrever facilidades e dificuldades para lidar com essas situações, e perspectivas de estratégias para o seu enfrentamento na ESF. Ao final, podiam falar livremente sobre a temática.

O contato com os participantes foi realizado nas UBS durante os dias da semana, nos turnos matutino ou vespertino, nos intervalos ou no final das atividades laborais, de forma que não interferiu nas atividades assistenciais.

Após o consentimento dos participantes, em uma sala reservada nas dependências das UBS, deu-se início à execução das entrevistas. Elas foram gravadas com o auxílio de um gravador digital MP4. Ao término de cada entrevista, foi realizada a validação das falas pelos participantes. Nesse momento, eles puderam ouvir o áudio das gravações dos seus relatos, possibilitando a sua retirada do estudo, o acréscimo de informação ou a modificação de quaisquer falas relatadas.

Após transcrição integral dos áudios e modificações segundo a validação pelos participantes, os resultados extraídos foram submetidos à análise temática de conteúdo. Segundo a proposta operativa de Minayo ${ }^{(16)}$, são fases desse tipo de análise: pré-análise - transcrição e organização das entrevistas para leitura flutuante; exploração do material - a partir de uma leitura minuciosa, operou-se a extração dos núcleos de compreensão do texto (temas), sendo observadas as suas regularidades, revelando três temas: o olhar dos enfermeiros acerca da violência infantil, as suas facilidades e dificuldades para o enfrentamento e as estratégias utilizadas para tal; por fim, o tratamento e a interpretação dos resultados - em que foram feitas inferências e interpretação dos dados e posterior agregação em categorias temáticas.

A pesquisa preservou o caráter voluntário de participação, assim como os demais preceitos éticos contidos na Resolução n.ㅇ 466/2012 do Conselho Nacional de Saúde. O projeto de pesquisa foi submetido à apreciação por Comitê de Ética em Pesquisa, e obteve aprovação em 12 de setembro de 2019, sob o Parecer n.o 3.571.651. Como forma de garantir o anonimato aos participantes, os nomes foram substituídos pela designação Enfermeiro seguida de números arábicos, conforme a ordem de inserção na pesquisa. A entrevista apresentou riscos mínimos de constrangimentos e desconfortos mitigados pela interrupção, quando solicitada pelo participante.

\section{Resultados}

O perfil dos participantes foi: 20 mulheres e 2 homens, entre 29 e 58 anos, com média de 40,45 anos de idade; 12 eram casados, 3 separados/divorciados, 6 solteiros e 1 viúvo; dentre os participantes 2 eram somente bacharéis, 19 especialistas e 1 mestre. Em relação ao tempo de formação acadêmica, houve o espaço temporal mínimo de 5 e máximo de 34 anos, com média de 15,09 anos; e, para o tempo de atuação na UBS, tempo mínimo de 2 anos e máximo de 22 anos, com média de 8,36 anos.

Os relatos dos enfermeiros permitiram identificar três categorias temáticas, conforme descritas a seguir:

\section{O olhar e a atitude do enfermeiro de Estratégia Saúde da Família acerca da violência infantil}

Pausas longas e silenciosas foram percebidas, quando se questionou sobre o olhar do 
enfermeiro acerca da violência infantil, mas logo revelou-se a inabilidade para lidar com tais situações, apesar do reconhecimento da necessidade de um olhar crítico e holístico, para identificação dos sinais de violência infantil:

Se a gente tivesse um olhar mais crítico para esse problema, a gente conseguiria detectar e ajudar um pouco mais [...] essas crianças. (Enfermeiro 1).

Acho interessante que, na saúde da família, a gente tem como ter um acompanhamento bem geral, e ver toda essa questão. Se tiver caso de violência, identificar e investigar a situação e ver se realmente precisa de um acompanhamento. (Enfermeiro 2).

O olhar do profissional enfermeiro deve ser como um todo né, holístico, como a gente atende muita criança na consulta. (Enfermeiro 3).

Sempre, no atendimento com as crianças, é com um exame fisico, buscando tanto dados importantes para o próprio atendimento, mas também sempre atento a indicios de que possa a criança estar sofrendo algum tipo de abuso, maltrato, violência dentro do seu domicílio ou até mesmo estar sendo vítima de outros tipos de violências. (Enfermeiro 10).

Hoje ela [violência infantil] é enraizada nas áreas de alta vulnerabilidade, como é a nossa área, que é uma área de periferia, uma área que o nível de instrução é muito baixo e o nível de pobreza é muito alto. E a gente consegue perceber que [...] ela está presente mais do que, muitas vezes, chegam até nós, dentro de consultório. (Enfermeiro 11).

Ao lidar com possíveis casos de violência infantil, o enfermeiro pode ter uma diversidade de atitudes, que, segundo os relatos, sempre inclui o trabalho multiprofissional. Inclusive, esse subsídio é utilizado como mecanismo de manutenção dos direitos da criança. Nessa perspectiva, obtém-se, como respostas, que a atitude dos enfermeiros para lidar com essa situação de vulnerabilidade está alinhada ao seu olhar interligado aos olhares de outros profissionais, em especial dos Agentes Comunitários de Saúde (ACS), como reflexo do vínculo com a comunidade:

[...] o agente de saúde também que está no domicílio [...] então, ele tem esse olhar que a gente não consegue ver. (Enfermeiro 2).

O agente de saúde é o porta-voz da comunidade para receber as informações da comunidade e passar para os profissionais. (Enfermeiro 9).

[A violência infantil é um] tema relevante, que deve ser abordado sempre nas reuniões com ACS [Agentes Comunitários de Saúde]. (Enfermeiro 17).

A violência infantil é uma situação presente [e] captada, na maioria das vezes, pelos ACS [Agentes Comunitários de Saúde]. (Enfermeiro 19).
Fatores intervenientes na abordagem do enfermeiro na Estratégia Saúde da Família às situações de violência infantil

Observou-se que não existiam facilidades do enfermeiro de ESF para detecção da violência infantil, pois o processo de trabalho era visto como adversidade, que trazia confronto e medo. Dessa forma, as respostas obtidas norteavam a percepção sobre uma falta de clareza em relação aos métodos que deviam ser adotados pelos enfermeiros e demais profissionais:

Não existe facilidade. Como eu disse, eu recebo a demanda e eu tenho muito cuidado em orientar os meus agentes de saúde e como observar a violência, como colher os dados antes de me trazer e como eles devem se comportar diante da comunidade. (Enfermeiro 7).

Na realidade, não existe nenbuma facilidade em lidar com a violência infantil [...] mais de $90 \%$ dos casos acontecem dentro do próprio seio familiar. Então, na minha opinião, não existe nenbuma facilidade, pelo contrário, existe muita dificuldade. (Enfermeiro 11).

A gente não tem facilidades, a gente tem dificuldades. Primeiro, nunca fomos treinados para... como abordar um caso como esse; então, a gente tem muito mais dificuldades do que facilidades. (Enfermeiro 13).

Não é fácil! Facilidade. É muito difícil você dizer assim "tem essa facilidade". (Enfermeiro 14).

Na realidade, não vejo nenhuma facilidade. Talvez a única facilidade seja você realmente ter uma aproximação com essa família. (Enfermeiro 18).

Muitas vezes, a equipe não quer se envolver [...] pela própria seguranç e tempo para realizar as visitas, e o perigo de determinadas regiões. (Enfermeiro 22).

Contudo, existiram relatos de possíveis benefícios e facilidades no processo de trabalho na ESF, que auxiliavam no enfrentamento a essas barreiras existentes na detecção de casos de violência infantil:

As facilidades são justamente essa questão de a gente ter esse acesso a essas crianças [...] A gente acompanha muitas crianças desde o pré-natal e a relação de confiança também com a mãe [...] facilita mais para a gente. (Enfermeiro 1).

Pode apontar como facilidade, seria a forma de detecção né, desses casos de violência, porque as crianças, elas são conbecidas da equipe, a família é conbecida. (Enfermeiro 10).

As facilidades estão no fato das equipes da Estratégia Saúde da Família estarem mais presentes na vida dessas familias. (Enfermeiro 15). 
Mais uma vez, quando inquiridos sobre as facilidades de cuidado à criança em situação de violência, os enfermeiros identificaram que a presença dos ACS na comunidade era um diferencial para a equipe como fator decisivo na identificação de situações de violência infantil, da mesma forma que revelaram a integração da rede intersetorial como facilitadora do cuidado:

A facilidade que a gente tem seria a proximidade do agente de saúde com o paciente. (Enfermeiro 4).

A facilidade é a questão de a gente ter o agente de saúde na área. (Enfermeiro 5).

A minha primeira ferramenta e mais, e mais óbvia na questão, é o agente de saúde. (Enfermeiro 9).

Mas temos parcerias que facilitam a assistência às famí lias com casos de violência infantil, como CREAS [Centro de Referência Especializada de Assistência Social], CRAS [Centro de Referência de Assistência Social], NASF [Núcleo Ampliado de Saúde da Família], Programa de Erradicação do Trabalho Infantil (PETI), e as escolas, por terem um contato a mais com os pais. (Enfermeiro 12).

O único facilitador é o Conselbo Tutelar, junto com a ESF [Estratégia Saúde da Família] onde são feitas visitas e, após isso, são encaminhadas para o Conselbo Tutelar. (Enfermeiro 20).

[...] o ACS [Agente Comunitário de Saúde] seria uma porta para nós ficarmos mais próximos dessas famílias e na própria consulta de enfermagem. (Enfermeiro 22).

Os relatos, entretanto, mostraram, como grande dificuldade para o enfrentamento, o reconhecimento, pela família, da necessidade de estabelecimento do vínculo com os profissionais, o que, em alguns casos, é sugestivo da violência perpetrada por aqueles que deveriam proteger a criança:

As dificuldades são, por exemplo, se a gente constatar alguma situação de suspeita e a gente não conseguir apoio de um familiar. (Enfermeiro 3).

É o tipo da coisa se o agente de saúde não tiver acesso ao domicilio. Tem gente que recusa a visita. (Enfermeiro 4).

As dificuldades, eu acho que até a questão da mudança do comportamento da família. (Enfermeiro 5).

A dificuldade maior é porque a violência infantil não é exposta, fica camuflada dentro da própria família. (Enfermeiro 12).

As dificuldades são muitas, porque, primeiro, para separar, começa de aí você julgar a relação mãe e filho é muito delicado. (Enfermeiro 14).

O maior dificultador é a resistência/omissão de pais, silêncio da criança violentada e dificuldade no encaminhamento ao serviço especializado, como a psicoterapia. (Enfermeiro 19).
Não existiam apenas as dificuldades de estabelecimento de vínculo com a família, mas também aquelas que apresentavam problemas de articulação da rede intersetorial - que se revelava dialógica -, ao mesmo tempo sendo o maior apoio sentido pelos enfermeiros:

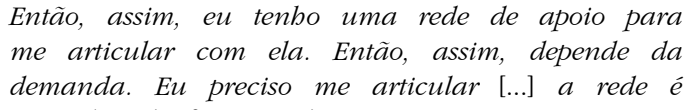

As dificuldades, elas estão justamente nas desigualdades e na situação de miséria que se encontram as pessoas que normalmente estão associadas ao baixo nível sociocultural e educacional, levando à ignorância, os hábitos e costumes nada condizentes com uma vida saudável, fisicamente e psicologicamente. (Enfermeiro 15).

A dificuldade é em relação à rede de apoio. (Enfermeiro 16).

O olhar dos enfermeiros, descrito na primeira categoria deste estudo, revelou-se com uma dificuldade importante no enfrentamento às situações de violência infantil na ESF:

Muitas vezes, o próprio enfermeiro e o agente de saúde não entendem a importância desse tema, não se preocupam em identificar, conbecer a área de abrangência local e entender a questão da área, o perfil da área, conhecer as demandas da área. (Enfermeiro 9).

Seria, às vezes, o despreparo de alguns profissionais, de reconbecimento de sinais de violência que, às vezes, não é um assunto muito discutido. Então, acaba que alguns profissionais acabam deixando passar despercebidos alguns sinais. (Enfermeiro 10).

Nunca notifiquei nenbum caso [...] nós profissionais não nos envolvemos nessa situação por conta das várias atividades do enfermeiro. Terminamos não focando tanto nesse quesito [violência infantil] e não atuando tanto na prevenção. (Enfermeiro 22).

\section{Estratégias empregadas pelo enfermeiro na Estratégia Saúde da Família para a abordagem da violência infantil}

Nesta categoria analítica, destacaram-se as perspectivas de estratégias que os enfermeiros de ESF vinham utilizando para suprir as dificuldades enfrentadas no dia a dia, relacionadas à violência infantil, tendo como principal potencializador a inserção do diálogo no processo de trabalho:

[Minha perspectiva] é questão mesmo de conscientização. Eu, por exemplo, gosto muito de conversar com as 
mães [...] a gente procura falar sobre isso nas próprias consultas. (Enfermeiro 1).

É ter um diálogo com a família. É tentar a cultura da paz dentro de casa. É estimular mesmo o respeito pelas crianças, tentar discutir com as famílias mais empobrecidas a questão da não violência. (Enfermeiro 10).

Através das nossas visitas, das nossas puericulturas, das nossas palestras tanto no posto de saúde como as palestras nas escolas [...] e nas buscas ativas. (Enfermeiro 15).

Realizar ações educativas com a família para prevenção de novas situações de violência, encaminhamento aos devidos órgãos, identificar violência infantil através de visita domiciliar. (Enfermeiro 21).

Observaram-se, nos relatos, perspectivas e oportunidades para o enfrentamento da violência infantil favorecidas pelo envolvimento com o cuidado holístico, o apoio social, o trabalho multiprofissional e a articulação da rede intersetorial:

O paciente vem sujo ou com a bigiene irregular, então, a gente fala com a mãe e orienta [...] em relação à higiene e cuidado, eficamos observando depois, porque, se a gente orientou, então não é para aquela criança voltar do mesmo jeito. (Enfermeiro 2).

Para abordar, bom, a gente tem que seguir todos os protocolos. A gente segue e tem a questão de notificação. No caso das notificações [...] a gente procura ser o mais sutil possível e tentar o máximo de respostas possíveis. (Enfermeiro 3).

Bom, o plano seria ser multiprofissional. (Enfermeiro 4).

E a gente sabe que tem a questão da notificação [...] uns setores mesmo, que a gente tem que chamar nessa bora, para poder ajudar. (Enfermeiro 5).

Esperava a parceria desses órgãos com a gente, da gente poder, porque não adianta só você, é relatar o caso, identificar o caso. (Enfermeiro 6).

É necessário que a equipe elou o profissional tenha um suporte adequado ao enfrentamento da violência, às situacões de estresses nos cuidados às vítimas e uma intersetorialidade com coesão nas ações destinadas à prevenção. (Enfermeiro 12).

Ter os órgãos competentes ao seu lado e a facilidade para você poder acioná-los quando necessário. (Enfermeiro 14).

[...] mais amparo dos órgãos envolvidos. As atividades educativas nessas comunidades também são importantes. (Enfermeiro 22).

\section{Discussão}

Os resultados deste estudo revelaram elementos do processo de trabalho dos enfermeiros de ESF, em especial aqueles relacionados às facilidades e dificuldades para o atendimento e reconhecimento de situações de violência infantil. Salienta-se a importância do estabelecimento de vínculo com a família e a rede intersetorial de atenção à criança. Os enfermeiros viam a ESF como uma possibilidade de interação entre família e serviço de saúde, fundamental ao combate da violência infantil. Contudo, descreveram dificuldades para elaboração desse cuidado, haja vista as limitações inerentes ao seu olhar para reconhecimento de sinais de abuso infantil e dificuldade de interlocução com demais polos da rede assistencial.

Como estratégia para sanar suas limitações inerentes ao reconhecimento de sinais indicativos de violência, mencionaram a importância do trabalho do ACS. Verbalizaram a figura desse profissional - integrante da equipe da ESF - como um agente investigador de acontecimentos, o que traz concordância com outro estudo ${ }^{(17)}$, que evidenciou a participação efetiva do ACS na comunidade, como ferramenta para viabilizar uma percepção sensível a respeito dos parâmetros de saúde da população adstrita, por ser esse profissional um morador daquela comunidade.

Os relatos dos enfermeiros permitiram identificar a importância do cuidado holístico e envolvimento do profissional com a pessoa, a família e a coletividade, por compreenderem que o processo de reconhecimento das situações de violência infantil pode ocorrer desde a visualização de sinais físicos e emocionais, por meio da consulta de enfermagem, até denúncias de casos pela comunidade. Dessa forma, concretiza-se em percepção que os enfermeiros evidenciaram, ao afirmarem que os ACS possuíam relevância na detecção de violência. Revela-se, porém, uma preocupação de que esse profissional possa ser visto pela população como um denunciador, vindo a sofrer represálias por parte dos agressores, como evidenciou pesquisa ${ }^{(18)}$ no Sudeste brasileiro, que demonstrou o cuidado de enfermagem em situações de violência infantil permeado por medos e ameaças, contribuindo para a subnotificação.

O conhecimento como base de mudança é um dos nortes para que a atuação da Enfermagem possa gerar diferencial contra a violência 
infantil, desde o processo de prevenção ao contexto de identificação dessa forma de agravo à saúde. Contudo, estudos ${ }^{(19-20)}$ identificaram que os profissionais de enfermagem não se sentem preparados para atuar nessas situações, o que corrobora os dados aqui obtidos, ressaltando a necessidade de treinamentos.

Este estudo revela que o olhar dos profissionais referentes à criança que sofre violência deve ser mais bem exercitado, visto que um relato revelou que o profissional nunca atendeu uma criança vítima de violência. Este é um dado impactante, considerando-se a realidade social nacional - aproximadamente 55\% dos registros de violação aos direitos humanos referem-se a crianças e adolescentes $^{(2)}$ - e a discrepância em relação aos relatos dos demais participantes.

Refletir sobre a necessidade de capacitação dos profissionais de saúde é primordial para o exercício de um cuidado de qualidade, holístico e acolhedor, com atenção às demandas de crianças e adolescentes, estabelecendo estratégias orientadas pelos determinantes da violência infantil. É notório que a programação da assistência de enfermagem revela um processo que beira a inespecificidade; isto é, são estratégias que não focam os determinantes da violência infantil e, portanto, caracterizam-se como mais um indicador de vulnerabilidade. As estratégias são pontuais e reativas, organizadas à medida que se identificam casos na comunidade. Os resultados demonstraram que há negligência dos serviços, principalmente no que diz respeito à organização de ações para prevenção da violência infantil.

Dessarte, a abordagem à violência infantil envolve o desenvolvimento de programas e estratégias de prevenção e controle, assim como a disponibilização de meios e insumos para sua efetivação. No entanto, o enfrentamento à violência infantil vai além de estratégias reativas, devendo envolver, sobretudo, políticas públicas intersetoriais que supram as necessidades e permitam o exercício pleno dos direitos à criança e ao adolescente $e^{(4)}$.

Os enfermeiros participantes desta pesquisa relataram dificuldades inerentes ao estabelecimento de vínculos, à articulação com a rede intersetorial, além de inabilidade para reconhecer casos de violência. No entanto, existem relatos de que pode haver benefícios e facilidades no processo de trabalho na ESF capazes de melhorar ou diminuir essas barreiras na detecção de casos de violência - como a necessidade de acompanhamento rotineiro das crianças -, para comprovação de condições de saúde em cadastros de programas sociais e assistenciais.

Os desafios presentes na abordagem da violência infantil ainda se relacionam ao contexto familiar. Dados demonstram que 52\% das denúncias de violações aos direitos da criança e do adolescente ocorrem na casa da vítima, sendo, em sua maioria, praticadas por pessoas próximas ao convívio família - pais, padrastos e tios -, das quais, em 40\% dos casos, a suspeita recai sobre a mãe. Esse dado pode estar relacionado à construção social da responsabilização da mãe pelos cuidados com os filhos, uma vez que a maior parte das violações referem-se a casos de negligência ${ }^{(2)}$.

Estudo $^{(21)}$ com o objetivo de analisar a rede de assistência e apoio social sob a perspectiva de familiares de crianças e adolescentes vítimas de abuso evidenciou lacunas na rede de apoio social da vítima. As relações mostraram-se enfraquecidas e de baixa intensidade, sendo o apoio majoritariamente instrumental e material. Reforçam ainda os achados deste estudo, ao destacar a importância do estabelecimento de relações afetivas, além de apoio e vínculo entre serviços e famílias. Percebe-se que as vulnerabilidades individual e coletiva estão imbricadas uma na outra, uma vez que a reprodução social de comportamentos aprendidos estabelece um ciclo de precarização do sistema de direitos da criança e do adolescente ${ }^{(4)}$.

São diversas as dificuldades que o enfermeiro pode ter com a família, em que as situações serão determinantes para as modificações sociais. Estudo destaca que os relatos dos enfermeiros revelam grande dificuldade de atuação, pois a identificação do agressor pode ser mascarada, e o tipo de violência praticada contra a criança, considerado situação "normal" pelo violentador, 
tendo em vista que expressam modelos aprendidos ao longo de gerações ${ }^{(4)}$.

Pesquisa ${ }^{(22)}$ avaliou o funcionamento da família e sua associação com o risco de maus-tratos em famílias que esperavam um bebê, e apontou que idade dos parceiros, educação das mães, problemas de saúde mental do pai, preocupação das mães com o consumo de álcool e dificuldades das mães em falar sobre os problemas da família são fatores relacionados ao risco aumentado de maus-tratos e abusos infantis. Assim, reforça-se que as condições de vulnerabilidade individual - que não se limitam à criança, mas envolvem valores culturais, crenças, idade, escolaridade, situação conjugal e situação laboral dos pais/responsáveis, e ainda a vivência de situações de violência no seio familiar - podem repercutir sob a forma de abusos, maus-tratos e negligência, enfraquecendo os vínculos afetivo-relacionais da criança ${ }^{(4)}$.

Neste estudo, os enfermeiros reconheceram a necessidade de dar visibilidade às discussões sobre violência infantil, pois ainda é uma temática negligenciada nos serviços de saúde, ainda que sejam fatores que incidem sobre a avaliação e o cumprimento das metas de crescimento e desenvolvimento das crianças. Não obstante, a valorização da temática pode ocasionar melhorias na assistência prestada pelo enfermeiro e por todos os profissionais de saúde, mitigando as condições de vulnerabilidades individuais e sociais. Para isso, é necessário reforçar o conhecimento dos enfermeiros, dando ênfase ao seu compromisso político e social na prevenção e no controle da violência infantil.

A ESF possui diversos mecanismos de diminuição de agravos, que se expressam por meio de processos educativos, mudanças de hábitos, visitas domiciliares, processos inclusivos à UBS, medidas medicamentosas, notificação compulsória, entre outros. Entretanto, quando se trata de problemas sociais - como a violência infantil -, somente a imersão em processos educativos, dialógicos e diplomáticos, com foco na mudança de comportamentos, pode minimizar os danos. No entanto, sabe-se que, isoladamente, os serviços de saúde não são suficientes; portanto, há necessidade do compartilhamento de responsabilidades e compromissos das diferentes instâncias da sociedade ${ }^{(4)}$.

No tocante ao enfrentamento da violência, mediante uso de protocolos instrucionais, rodas de conversas, palestras e atuação nos serviços de assistência, como a escola, foram estratégias mencionadas pelos entrevistados como potenciais; logo, é evidente que os enfermeiros compreendiam a importância da articulação da rede intersetorial para a proteção da infância. Estudo $^{(23)}$ corrobora a relevância do trabalho desses profissionais, ao mostrar impacto positivo de um programa de visitas domiciliares de enfermeiras na redução dos maus-tratos infantis entre os participantes. Dessa forma, as perspectivas de enfermeiros de ESF, para reduzir a vulnerabilidade da criança e do adolescente à violência, envolve a educação em saúde, por meio do diálogo interprofissional e com a comunidade, e a articulação com a rede intersetorial de atenção à criança.

Os enfermeiros relataram ainda a importância da anamnese e do exame clínico do paciente na APS, mediante uma consulta de enfermagem rigorosa e atenta, com o intuito de notar alguma inconformidade que possa estar presente nesse corpo e nessa mente e, em caso de sinais de violência, seguir protocolos que são facilitadores desse processo. Assim, compreender a criança e o adolescente como um grupo vulnerável per se $e^{(4)}$, é essencial no processo de trabalho do enfermeiro na ESF.

Nesse sentido, observa-se que os enfermeiros possuem papel fundamental na identificação de sinais e fatores associados à violência infantil, haja vista que são os profissionais mais próximos dos pacientes e, portanto, capazes de realizar uma abordagem padronizada e baseada em protocolos. Estudo relata que se soma à inviabilização da violência infantil na sociedade o fato de os enfermeiros, por estarem mais atentos a aspectos clínicos, apresentarem dificuldades para estabelecer problemas de enfermagem para situações de violência infantil. Apesar disso, os autores identificaram problemas principalmente relacionados ao ambiente, às relações interpessoais e à aprendizagem. Referendam a urgência em se reformular os currículos de formação para 
a abordagem do raciocínio clínico e da temática violência infantil $^{(24)}$.

Por apresentar um limiar muito próximo da criminologia, nesse contexto, a percepção de enfermeiros sobre a abordagem em casos de violência infantil deve ser cautelosa e prudente, sem pré-julgamentos, como evidenciado nos relatos. No entanto, estudo ${ }^{(25)}$ sueco reforça a importância da denúncia dos casos e revela que mais da metade dos enfermeiros atuantes no ambiente escolar já identificaram ao menos um caso suspeito de criança em sofrimento por abuso físico ou psicológico, sendo comuns os casos de abuso.

De modo geral, esta pesquisa revelou que as estratégias aplicadas pelo enfermeiro da ESF estão focadas nas vulnerabilidades individuais, apesar de as políticas e os programas já reforçarem o caráter coletivo da vulnerabilidade da criança e do adolescente à violência, como reproduzido em outro estudo ${ }^{(4)}$.

Dentre as limitações do estudo, ressalta-se o fato de ter sido realizado com amostra pequena de enfermeiros e de uma única região, além da curta duração das entrevistas. Portanto, os achados refletem uma porção restrita do país. Outro fator limitante foi a média de tempo das entrevistas, que, sendo curtas, podem ter oferecido pouco material para a análise.

Apesar das limitações, o estudo mostra que é possível, dentro da ESF, elaborar estratégias para o enfrentamento da violência infantil pautadas no diálogo, no trabalho multiprofissional e na intersetorialidade, com ênfase na dimensão coletiva de vulnerabilidade. Possibilita ainda a reflexão da prática do enfermeiro e sua interconexão com o processo de trabalho dos demais membros da equipe e áreas afins envolvidas no enfrentamento dessa situação.

\section{Considerações finais}

Este estudo revelou uma compreensão ampla das percepções dos enfermeiros de ESF acerca da violência infantil. Os profissionais apontaram, como fatores intervenientes na abordagem da violência infantil na ESF, as seguintes dificuldades: reconhecimento dos sinais de violência, estabelecimento de vínculos com a família e articulação com a rede intersetorial. Esses profissionais mostraram que transitam entre os cuidados de saúde e a denúncia às esferas criminais.

As estratégias empregadas pelo enfermeiro da ESF mostraram-se fragmentadas e focadas nas vulnerabilidades individuais da criança e do adolescente às situações de violência, contrariamente ao fortalecimento dos determinantes sociais e programáticos para o seu enfrentamento. Pelos relatos, ficou evidente que fortalecer vínculos com a comunidade é primordial para o enfrentamento, assim como o processo de trabalho do ACS como membro da equipe in loco. Em relação ao cotidiano do trabalho na ESF, são importantes a educação em saúde e a articulação com a rede intersetorial, a fim de garantir desenvolvimento e crescimento saudáveis à criança.

\section{Colaborações:}

1 - concepção, projeto, análise e interpretação dos dados: Ana Lícia Barbosa Serra Silva, Laura Cristinne Santos Macatrão Bacellar Couto, Mikaeli Macêdo de Oliveira e Carolinne Kilcia Carvalho Sena Damasceno;

2 - redação do artigo e revisão crítica relevante do conteúdo intelectual: Ana Lícia Barbosa Serra Silva, Laura Cristinne Santos Macatrão Bacellar Couto, Mikaeli Macêdo de Oliveira, Fernanda Cláudia Miranda Amorim, Juliana Macêdo Magalhães, Kayo Henrique Jardel Feitosa Sousa e Carolinne Kilcia Carvalho Sena Damasceno;

3 - aprovação final da versão a ser publicada: Ana Lícia Barbosa Serra Silva, Laura Cristinne Santos Macatrão Bacellar Couto, Mikaeli Macêdo de Oliveira, Fernanda Cláudia Miranda Amorim, Juliana Macêdo Magalhães, Kayo Henrique Jardel Feitosa Sousa e Carolinne Kilcia Carvalho Sena Damasceno.

\section{Referências}

1. World Health Organization. Global status report on violence prevention 2014 [Internet]. Geneva; 2014 
[cited 2018 Aug 31]. Available from: http://www. undp.org/content/dam/undp/library/corporate/ Reports/UNDP-GVA-violence-2014.pdf

2. Brasil. Ministério de Estado da Mulher, da Família e dos Direitos Humanos. Ouvidoria Nacional de Direitos Humanos. Disque Direitos Humanos: relatório 2019 [Internet]. Brasília (DF); 2020 [cited 2021 Mar 29] Available from: https://www.gov. $\mathrm{br} / \mathrm{mdh} / \mathrm{pt}$-br/assuntos/noticias/2020-2/maio/ Disque100Relatorio.pdf

3. Barreto CSLA, Araújo RPC, Martins Júnior DF, Barreto Filho RC, Costa MCO. Perfil da violência que vitima crianças no estado da Bahia, segundo registros do Sistema de Gerenciamento Estatístico (SGE) da Secretaria de Segurança Pública. Rev Saúde Col UEFS. 2018;8:5-15. DOI: 10.13102/ rscdauefs.v8.2975

4. Hino P, Takahashi RF, Nichiata LYI, Apostólico MR, Taminato $M$, Fernandes $\mathrm{H}$. Interfaces of vulnerability dimensions in violence against children. Rev Bras Enferm. 2019;72(Suppl 3):343-7. DOI: 10.1590/0034-71672018-0463

5. Maia JN, Ferrari RAP, Gabani FL, Tacla MTGM, Reis TB, Fernandes MLC. Violência contra criança: cotidiano de profissionais da Atenção Primária à Saúde. Rev Rene. 2016;17(5):593-601. DOI: $10.15253 / 2175-6783.2016000500003$

6. Garbin CAS, Araújo PC, Rovida TAS, Rocha AC, Arcieri RM, Garbin AJI. Violência na população infantil: perfil epidemiológico dos abusos verificados no ambiente escolar. Ciênc Plural [Internet]. 2016 [cited 2020 May 31];2(2):41-54. Available from: https://periodicos.ufrn.br/rcp/ article/view/10122

7. Morais RLGL, Sales ZN, Rodrigues VP. Limits and possibilities in coping violence against children and teens. J Nurs UFPE on line. 2015;9(Suppl 3):7664-81. DOI: 10.5205/reuol. 7049-61452-1-ED.0903supl201521

8. Schneider S. Associations between childhood exposure to community violence, child maltreatment and school outcomes. Chil Abuse Negl. 2020;104:104473. DOI: 10.1016/j.chiabu. 2020.104473

9. Egry EY, Apostólico MR, Morais TCP, Lisboa CCR. Coping with child violence in primary care: how do professionals perceive it? Rev Bras Enferm. 2017;70(1):113-9. DOI: 10.1590/ 0034-7167-2016-0009
10. Ferguson CJ. Child Abuse, Spanking and Adult Dating Violence: A Replication Study of Temple et al., 2018. Psychiatr Q. 2020:91(3)835-40. DOI: 10.1007/s11126-020-09742-5

11. Egry EY, Apostólico MR, Morais TCP. Reporting child violence, health care flows and work process of primary health care professionals. Ciênc saúde coletiva. 2018;23(1):83-92. DOI: 10.1590/1413-81232018231.22062017

12. Brasil. Ministério da Saúde. Secretaria de Atenção à Saúde. Departamento de Ações Programáticas Estratégicas. Linha de Cuidado para a Atenção Integral à Saúde de Crianças, Adolescentes e suas Famílias em Situação de Violências: orientação para gestores e profissionais de saúde [Internet]. Brasília (DF); 2014 [cited 2019 Aug 31]. Available from: https://bvsms.saude.gov.br/bvs/publicacoes/ linha_cuidado_atencao_integral_saude.pdf

13. Yakuwa M, Neill S, Mello D. Nursing strategies for child health surveillance. Rev Latino-Am Enfermagem. 2018;26:e3007. DOI: $10.1590 / 1518-8345.2434 .3007$

14. European Union Agency for Fundamental Rights. Provisions on professionals' legal obligation to report cases of child abuse, neglect and violence [Internet]. Viena (AUT); 2015 [cited 2019 Aug 31]. Available from: https://fra. europa.eu/en/publication/2015/mappingchild-protection-systems-eu/reporting-1

15. Mirlashari J, Jahanbani J, Begjani J. Addiction, childhood experiences and nurse's role in prevention: a qualitative study. East Mediterr Health J. 2020;26(2):212-8. DOI: 10.26719/2020.26. 2.212

16. Minayo MCS. O desafio do conhecimento: pesquisa qualitativa em saúde. São Paulo: Hucitec; 2014.

17. Apostólico MR, Hino P, Egry EY. Possibilities for addressing child abuse in systematized nursing consultations. RevEscEnfermUSP. 2013;47(2):320-7. DOI: $10.1590 /$ S0080-62342013000200007

18. Leite JT, Beserra MA, Scatena L, Silva LMP, Ferriani MGC. Coping with domestic violence against children and adolescents from the perspective of primary care nurses. Rev Gaúcha Enferm. 2016;37(2):e55796. DOI: 10.1590/1983-1447.2016.02.55796

19. Silva MS, Milbrath VM, Santos BA, Bazzan JS, Gabatz RIB, Freitag VL. Nursing care for child/ adolescent victims of violence: integrative review. 
Rev Fun Care Online. 2020;12:115-22. DOI: 10.9789/2175-5361.rpcfo.v12.7102

20. Martins-Júnior PA, Ribeiro DC, Peruch GSO, Paiva SM, Marques LS, Ramos-Jorge ML. Physical abuse of children and adolescents: do health professionals perceive and denounce? Ciênc saúde coletiva. 2019;24(7):2609-16. DOI: 10.1590/1413-81232018247.19482017

21. Carlos DM, Silva LMP, Beserra MA, Aragão AS, Gregory A, Ferriani MGC. Social support network of family members of abused children and adolescents: perspectives and possibilities. J Clin Nurs. 2019;28(5-6):814-27. DOI: 10.1111/ jocn. 14665

22. Lepistö S, Ellonen N, Helminen M, Paavilainen E. The family health, functioning, social support and child maltreatment risk of families expecting a baby. J Clin Nurs. 2017;26(15-16):2439-51. DOI: 10.1111/jocn. 13602
23. Eckenrode J, Campa MI, Morris PA, Henderson CR, Bolger KE, Kitzman $\mathrm{H}$, et al. The Prevention of Child Maltreatment Through the Nurse Family Partnership Program: Mediating Effects in a Long-Term Follow-Up Study. Child Maltreat. 2017;22(2):92-9. DOI: $10.1177 / 1077559516685185$

24. Apostólico MR, Egry EY, Fornari LF, Gessner R. Accuracy of nursing diagnoses for identifying domestic violence against children. Rev Esc Enferm USP. 2017;51:e03290. DOI: 10.1590/ s1980-220x2017019103290

25. Sundler AJ, Whilson M, Darcy L, Larsson M. Swedish School Nurses' Experiences of Child Abuse. J Sch Nurs. 2019;20(10):1-9. DOI: $10.1177 / 1059840519863843$

Recebido: 10 de novembro de 2020 Aprovado: 12 de abril de 2021 Publicado: 7 de maio de 2021

A Revista Baiana de Enfermagem utiliza a Licença Creative Commons - Atribuição-NãoComercial 4.0 Internacional. https://creativecommons.org/licenses/by-nc/4.0/ Este artigo é de acesso aberto distribuído sob os termos da Licença Creative Commons (CC BY-NC). Esta licença permite que outros remixem, adaptem e criem a partir do seu trabalho para fins não comerciais. Embora os novos trabalhos tenham de lhe atribuir o devido crédito e não possam ser usados para fins comerciais, os usuários não têm de licenciar esses trabalhos derivados sob os mesmos termos. 